\title{
Affect philosophy meets incongruity: about transformative potentials in comic laughter
}

\author{
Mark Weeks \\ Nagoya University, Japan \\ mark@ilas.nagoya-u.ac.jp
}

\begin{abstract}
The emergence of philosophical affect theory, sourced substantially in Continental philosophy, has intensified scholarly attention around affective potentials in laughter. However, the relationship between laughter's affect and the comic remains a complicated one for researchers, with some maintaining that the two should be approached separately (Emmerson 2019, Parvulescu 2010). While there is a credible academic rationale for drawing precise distinctions, the present article takes an integrative approach to laughter and the comic. It analyses, then synthesises, points of convergence between key texts in affect philosophy and certain elements of incongruity-based humour theory. Specifically, the article seeks to demonstrate that some integration can bring insight and clarity to discussion of transformative potentials sometimes attributed to forms of comic laughter, especially within cultural studies and social science following the philosophy of Deleuze. This approach may also usefully complicate the concept of incongruity itself.
\end{abstract}

Keywords: affect, Deleuze, laughter, humour, incongruity, Nietzsche, nomad.

\section{Introduction}

The affect philosopher, Massumi, identifies laughter, along with anger, as "perhaps the most powerful" of affective expressions (2015: 8). Yet scholarship on laughter drawing upon the philosophy of affect (which must be distinguished from affect psychology) maintains a complicated relationship with the comic. The geographer Emmerson observes that studies ostensibly of laughter, even those alluding to affect, often become analyses of the comical that leave laughter aside (2017: 2083). Meanwhile, the theorisation of humour continues to be pursued with relatively little reference to affect in the contemporary philosophical sense. To a significant degree, distinguishing laughter from the comic is defensible in terms of scholarly exactitude, but for the future of research it is useful to ask if the two fields, humour theory and affect philosophy, have more to offer each other.

Without pursuing a comprehensive theory, the present article examines the interaction of laughter and the comic, of affect and cause, by analysing points of convergence between texts of affect philosophy and a certain area of humour theory. Specifically, the aim is to demonstrate 
that, while the comic is certainly not reducible to incongruity, the concept of incongruity can bring useful complexity and nuance to the delineation of comic laughter as a potentially transformative affect; at the same time, affect-oriented philosophy may extend the range of humour scholarship by conceptualising incongruity-driven laughter in terms of embodied transformative potentials. It is not to suggest that laughter or the comic in isolation may not induce change, or that studying the two in isolation is without value; the intention is simply to focus on their nexus. As far as I am able to ascertain, such an endeavour has not been comprehensively undertaken before.

The article takes the following trajectory. First, while furnishing definitions of the terms transformative potential and affect as they are used, I describe a specific tension arising in some affect-centred academic discourse around laughter as it confronts conventional humour scholarship. I then elucidate how certain work by Massumi $(1995,2015)$ reveals points of convergence between philosophical theory of affect and the concept of comic incongruity. This leads to discussion of how affect philosophy may work with incongruity-based humour theory to further explore the connection between the degree of unresolved incongruity and transformative potential in comic laughter. I then extend the analysis into writing by Deleuze, a philosophical foundation for Massumi's own work. The focus is Deleuze's essay "Nomad thought" (1977), in which comic laughter is a prominent theme and incongruity is broached. Deleuze's philosophical vocabulary is radical and demanding upon readers, yet it provides tools for complicating the concept of incongruity itself in ways that could be useful for humour theorists across disciplines considering differences between radical, progressive and conservative strains of laughably comic experience.

\section{Binary tensions: laughter/comedy and affect/semiotics}

The relationship between laughter and the comic remains a challenge for scholars across fields. Not all laughter is generated by the comical (Provine 2000), not all comical events induce laughter (Morreall 1983), yet the two are often contiguous and strongly associated (Holt \& Glenn 2013). Emmerson (2017: 2083) remarks that laughter has "mostly remained a fleeting referent" in scholarship in the social sciences as it has gravitated towards analysis of the comical, as in "humour, jokes, the ridiculous or the grotesque." Citing numerous articles, he observes a change: "there is a growing body of work with laughter much closer to its core" (Emmerson 2017: 2083). In support of the perceived trend, Emmerson (2017: 2083) argues for studying laughter separately from what may precede it: "This is not to downgrade humour, but rather to recognise humour and laughter as different phenomena, and thus to establish further analytical precision."

Analytical precision is not all that is at stake, however. Emmerson (2019: 144) notes that much of the new work focusing on laughter is "addressing different forms of (micro)political life." Referring to Bergson's (1911) conception of laughter as a means to chastise behaviour, he acknowledges that laughter may be used to reinforce structures of control (Emmerson 2019: 144), a point argued extensively by Billig (2005). However, Emmerson's own article and the works it cites are primarily concerned with a contrary movement, focusing on transformative effects:

Laughter can also challenge these disciplinary mechanisms: through disruption of power (Hughes 2016), providing alternative narratives (Brigstocke 2014) and creating 'sensuous solidarities' (Routledge 2012) - all of which can engender bodies with a capacity to exceed the control of structural powers (Emmerson 2019: 144). 
The latter is what is meant in the present article by "transformative potential," referring to the political in its broadest sense, the potential to breach structural constraints or inertia at any level of life, society or existence in general.

Emmerson (2019: 144) remarks a common denominator in such works on comic transformation, their eschewing reduction of laughter to purely semiotic functions in order to "touch on its position as affective, that is to say, its capacities to prompt actions and affections within and between bodies." Collectively, they thus reflect the "affective turn" in areas of the humanities and social sciences since the late 20th century, a shift with respect to a perceived ascendency of language and semiotically based cultural analysis in the preceding decades, sometimes identified as the "linguistic turn" or "semiotic turn" (Braidotti 2011: 5).

Affect, as it is used here, is not reducible to emotions or individual humans. In the foreword to Deleuze \& Guattari's A Thousand Plateaus, Massumi (1987: xvi) defines affect as "a prepersonal intensity corresponding to the passage from one experiential state of the body to another and implying an augmentation or diminution in that body's capacity to act." Elsewhere, Massumi (2015: 7) defines it thus: "Affect is simply a body movement looked at from the point of view of its potential - its capacity to come to be, or better, to do." A source for these definitions is the 17th-century philosopher Spinoza's (1994: 72) assertion concerning philosophers' understanding of the human: "They do not know what the body can do." It reflects an orientation in affect philosophy toward the potentialities of embodied transformative processes moving into, and generating, futures.

This affect-centred academic orientation informs Emmerson's concern to prevent laughter's affect being marginalised or diluted within linguistic or literary analyses of associated comedy and related emotions. Emmerson's 2017 and 2019 articles allude to a commonly cited text on laughter within the affective turn, Parvulescu's book Laughter: Notes on a Passion (2010). It, too, acknowledges the operations of comic triggers, but is less compromising with regard to humour theory, asserting from the beginning that "this book leaves the old question of what makes us laugh behind." It argues that, while typically "theories of laughter share a focus on the [comical] object of laughter," from an affective standpoint "the question of laughter's cause or origin is beside the point" (Parvulescu 2010: 3-4).

Consequently, Parvulescu (2010) only briefly glosses a few selected writers on humour theory, and is scathing of the incongruity model that remains central to much mainstream humour theory in one form or another. In a footnote rejecting such approaches, Parvulescu (2010) is dismissive specifically of Kant, who offered a formula that has long served as a touchstone for incongruity theory: "Laughter is an affection arising from a strained expectation being suddenly reduced to nothing" (Kant 1952: 199). Parvulescu (2010: 185-6n) goes so far as to cite the observation by the philosopher Nancy $(2008: 15,134)$ that Kant's incongruity theory "reveals the inadequacy of the Philosopher." Thus, while exploring the semiotics of laughter itself, sometimes called "affect display," Parvulescu skirts engagement with structural analysis of the comic.

From the other side, engagement with affect philosophy from humour theoretical perspectives outside of philosophy and cultural studies has been muted, perhaps in part because affect philosophy gives such attention to transformative potentials alongside identifiable norms. Perhaps too because the vocabulary can be rather challenging. But do the two sides really have so little to say to each other? Close reading of Massumi's work $(1995,2015)$ suggests possible ground for more cross-disciplinary dialogue around the issues of laughter and incongruity. 


\section{Affect, incongruity and interruption}

What makes laughter such a powerful affect, according to Massumi (2015: 8), is its capacity to "interrupt a situation," its embodied kinetic eruption through the world, quite apart from the content of humour that may have induced it, and to some degree even from emotions emanating from that humour. In this section, I will undertake a synthetic movement, examining how this actually approaches some incongruity-based explanations of comic experience, especially where such explanations suggest a temporal disjunction.

Massumi delineates the scope and implications of affect in the seminal essay "The autonomy of affect" (1995). There, a comic relationship with affect is briefly raised in discussion of former US President Reagan. Massumi considers Reagan's communicative effectiveness, observing an irony in his being labelled the "great communicator" by some, when his public addresses could at times be characterised by "gestural idiocy" and "verbal incoherence" (1995: 102). This is an element of Reagan's rhetorical style earlier analysed by the cultural philosopher Postman (1985) and something similar is examined in work on the force of President Trump's comical gesturing by Hall et al. (2016). Massumi observes that Reagan's unscripted speeches could be "hilariously" discordant and were often "greeted by howls of laughter" (1995: 100): "It wasn't that people didn't hear his verbal fumbling or recognise the incoherence of his thoughts. They [the speeches] were the butt of constant jokes" (1995: 101-102).

Massumi (1995: 85) claims that it is precisely when discourse is punctuated by incoherence that Reagan achieved most impact, sometimes specifically comic but in any case affective. This is distinguished from thematic content, which is seen to be processed in terms of continuity and emotional "depth reactions." The affect Massumi is concerned with tends to throw bodies out of predictable discursive flow. The repetition of sudden incoherencies in verbal or gestural communication "cuts its [the speech's] continuity into a potentially infinite series of submovements punctuated by jerks. [...] [E]ach jerk is a critical point, a bifurcation point" (Massumi 1995: 102). Although not referring to comic effect alone, this description is notable for its convergence with incongruity models of humour. The reference to "bifurcation" recalls Koestler's (1964: 35) association of the comic with bisociation, defined as "the clash of [...] two mutually incompatible codes." This is academically formalised (as part of the semiotic turn) in the semantic theory of Raskin (1979: 332, 325) with its notion of competing scripts. In Massumi's case the focus is not upon the semantics but upon what may be achieved by the clash itself, referred to as affective "asignifying intensity" (1995: 102), one manifestation of which is laughter. In focusing upon the experience of incongruity rather than meaning, this is somewhat similar to Morreall's (1989: 10-18) notion of the enjoyment of incongruity, although here the emphasis is less upon the exercise of rational detachment, more upon disruption and affect.

While Massumi acknowledges structure in referring both to "bifurcation" and to "crossing of semantic wires" (1995: 85), it is the disrupted flow of discourse or cognition that is considered decisive: "power is in interruption" (1995: 102). That is to say, the principle force of affect/intensity is its subversion of something deemed more fundamental than either meaning or structure: time. Its effect is to "suspend the linear progress of the narrative present from past to future. [...] It is a state of suspense, potentially of disruption. It's like a temporal sink, a hole in time" (Massumi 1995: 86). The affective intensity of comic laughter under certain circumstances may thus serve what Massumi refers to elsewhere as "immediation" (2015: 146176) and "intensive deformation," potentially releasing bodies from conservative homeostasis, "a tendency of the present to extend into the future in conformity with the past" (2015: 182). It is in this respect that laughter is viewed as holding special transformative potential. In the case of comic laughter, this does not imply that the comic text or event is devoid of meaning, only that meaning is not the only, and perhaps not the most impactful or important, outcome. 
Some tentative empirical investigation of time in the context of comic experience has been undertaken by dedicated humour theorists (notably Attardo \& Pickering's 2011 study of comic timing), and cultural philosophy has also approached the topic, exemplified by Amir's (2010) "Humour and time." In the past two decades, roughly corresponding to the affective turn, a temporal disjunction has been associated with laughter by several philosophy and culture scholars, including Kimmel (1998), Critchley (2002: 7), Weeks (2002, 2013), and Lingis (2005: 91). Parvulescu, as part of the trend, writes, "What the burst of laughter bursts is time itself" (2010: 14). Yet Parvulescu's work divorces this affect from the interruption achieved through incongruity. It thus identifies a temporal break with laughter while missing an implication raised by Massumi's work and humour theory: strictly speaking, where the autonomic affect of laughter is induced by the comical, the interruption is not launched by laughter itself but by a "bifurcation" in the comic event. In laughter, that comic interruption is conspicuously amplified, reverberating to another level of embodied potential.

A certain incongruity-based model of affective temporal disruption was actually posited by philosophers long before any linguistic/affective divide, as discussed by Weeks (2002) and briefly alluded to by Billig (2005: 116): "There is a constant but barely discussed element in previous laughter theories: the assumption of a sudden break in time." One of the most famous instances is Kant's (1952: 199) aforementioned assertion that "Laughter is an affection arising from a strained expectation being suddenly reduced to nothing." In this view, what is destroyed momentarily in the confrontation with incongruity under certain "playful" conditions is a tension of futurity, the "strained expectation." Later, Schopenhauer (1989: 280) takes up incongruity theory and identifies a sudden shift from a common temporality of "conception [...] the medium of the past, the future, and of seriousness" into what he calls "perception [...] the medium of the present, of enjoyment and gaiety." These passages together are remarkable in their statement of affective change in terms strikingly close to Massumi's $(1995: 86,85)$ description of affect, its capacity to "momentarily suspend the linear progress of the narrative present from past to future," as "an autonomic remainder [...] outside expectation and adaptation [...] disconnected from meaningful sequencing."

In summary, affect philosophy affirms the significance of the concept of a temporal shift for understanding the operations of comic laughter, suggesting such laughter is not reducible to preceding semantic content, emotion or structure alone. Such affect is principally a product of interruption. In Massumi's reading of Reagan's comic discordances, this can be potent and impactful in itself. At the same time, to divorce laughter's affect from identifiable comic causes, where they exist, is to render it unnecessarily opaque, and to understate the significance of the initiating incongruity from which spontaneous laughter often resonates. It is also likely to understate complexities and nuances at the point of disruption, which may produce affects in vastly different directions, from the transformative to the conservative.

\section{Incongruity, non-resolution and transformative potential}

Drawing on the temporal conception of comic affect, this section examines how affect philosophy may work with incongruity-based humour theory to articulate a complex negotiation between laughter and discursive continuity in the comic, specifically as it relates to notions of transformative potential. Affect philosophy asserts that the pleasurable intensity of laughter is a significant event in itself, apart from the production of meaning. As an interruption, it is potentially a site of transformation because it removes bodies from familiar continuity. But what if that disruption is expected or otherwise ameliorated through subjugation to forms of continuity? Take, for example, the comical discontinuities Massumi (1995) discerns in Reagan's 
speeches. While Massumi contends they had affective force, could they really be viewed as transformative in a narrow political sense given the conservative politics of the speaker? Possibly not. Massumi (1995: 102) writes: "The two levels of interruption, those of linear movement and conventional progressions of meaning, were held together by the one Reagan feature that did, I think, hold positive appeal - the timbre of his voice, that beautifully vibratory voice." Thus, along with affect at the surface level of comical disjunction there was a "deep" emotional resonance of vocal quality, expressing apparent confidence, which was associated with the man and endured through time. This did not cancel the comic affect but politically harnessed it: "Confidence is the emotional translation of affect as capturable life potential; it is a particular emotional expression. [...] Reagan transmitted vitality, virtuality, tendency, in sickness and interruption" (Massumi 1995: 103, emphasis in the original). This is an interpretation of politically deployed affective potential sourced in comical incongruity that might again be usefully applied to Trump's verbal and gestural performance.

There is a vast array of devices through which the comically affective event may be restored to varying degrees of sense, familiarity, and continuity. According to incongruityresolution theory, a degree of bridging may be achieved by something as simple as the shared sounds connecting disparate meanings in puns (Ritchie 1999). A discursive temporal bridge may also be afforded effectively through content, as in pointed, satirical or tendentious humour that renders the comedy communicatively productive. Viewed from a broader temporal perspective, a bridge may be provided by an overarching narrative within which comic events occur, as in mainstream sitcoms. There, some degree of resolution may also be achieved by attributing certain comically interruptive incongruities to predictable character traits. If an incongruous action is consistent with a familiar character, say Larry in Curb Your Enthusiasm, then it is not entirely unexpected, and therefore not thoroughly undermining sensible discursive continuity, even if the audience laughs. Inconsistency and incoherence in politicians consumed as "characters" such as Reagan (Postman 1985) and more recently Trump (Taibbi 2018: 105-109), can be seen to be processed and enjoyed in similar ways, perhaps to the extent that critical political disquiet and action may be dissipated in laughter even as affective disjunctions are operating. It is a complex process with political ramifications.

This suggests that comic disruption could hold most radical affective potential when it is not resolved in such ways. Yet, as shown, there is a vast array of devices for mitigating incongruity-generated interruption. Just how radical unmitigated non-resolution can be is evidenced in Freud's struggle with nonsense in Jokes and their Relation to the Unconscious (1960, first published in German in 1905). Freud observes in a footnote that jokes evolve from "a core of original pleasure in play" and that meaningful discourse is then constructed around that play in order to pre-empt its censure as unproductive behaviour (Freud 1960: 138n). Yet Freud's book does little to deal with nonsensical, unresolved humour other than to concede in the footnote that such jokes "have not had due attention paid to them" (Freud 1960: 138n). An attempt to address the insufficiency is then made in the 1912 edition: an addendum is added to the footnote in which two examples of nonsense jokes are presented for analysis:

A man at the dinner table who was being handed fish dipped his hands twice in the mayonnaise and then ran them through his hair. When his neighbour looked at him in astonishment, he seemed to notice his mistake and apologised: "I'm so sorry, I thought it was spinach."

"Life is like a suspension bridge," said one man - "Why is that?" asked the other - "How should I know?" was the reply (Freud 1960: 138-139n). 
Freud concedes that these two jokes "really are nonsense" and that a "pleasure in nonsense" is enjoyed. Yet this is not regarded as sufficient motivation for their dissemination: "These jokes are not entirely without a purpose, they are a 'take in,' and give the person who tells them a certain amount of pleasure in misleading and annoying his hearer. The latter then damps down his annoyance by determining to tell them himself later on" (Freud 1960: 139n). Reduced to a concatenation of annoyance and displaced vengeance, laughter is absented from the discussion. Eastman (1937: 290) observes that Freud "cannot himself see that pure nonsense is ever comic." The reason for that, Plessner (1970: 104) claims, is that "Freud sees the natural basis of systematisation in the point of the joke," that is, in the semantic product. Freud's battle with nonsense, then, is revealing of a certain resistance to the species of comic which produces virtually nothing but the affect of laughter. It is the simplest instantiation of what is modelled in incongruity theory, yet precisely because here the subversion of semantic productivity and thus productive time is unredeemed, it may also be most challenging. The interruptive affect is unmitigated.

According to Massumi (2015: 11), “[u]ncertainty produces an affective change in the situation," because it induces intensive immediacy. If incongruity-induced laughter enacts a subversion of temporal continuity, sending sudden disruptive waves of paroxysm across bodies, one might expect it to be confronted with restriction or at least attempts to restore it to productive discursive time. If one follows that affect-centred line of thinking, then the degree to which comic laughter is attributable to some meaning would influence its level and areas of acceptance, with ideological implications. This finds some support in empirical research by Ruch \& Hehl (1986a, 1986b) and Hehl \& Ruch (1990) on personality types and humour preferences (recently taken up by Sulejmanov et al. 2018) which shows that "conservatives enjoy and laugh at incongruities, only if they are resolvable" (Hehl \& Ruch 1990: 444) and that they are less likely to enjoy texts involving unresolved incongruity, such as Gary Larson's Far Side cartoons or Monty Python, for example. That is, those who are more attached to continuation of the past are more likely to demand meaningful semantic bridging of the "time sink" opened with laughter. As reported by Martin (2006: 203),

individuals who espouse more conservative views (as measured by scales of intolerance of minorities, militarism, religious fundamentalism, education to submission, traditional family ideology, capitalism, economic values, and value orthodoxy) and authoritarian attitudes (punitiveness, intolerance of ambiguity, law-and-order attitude) are more likely to enjoy humour in which the incongruity is resolved and one can 'get the joke', and to dislike more bizarre or zany humour that does not seem to 'make sense'.

\section{Conversely,}

individuals with high scores on measures of sensation seeking, as well as related constructs such as venturesomeness and hedonism, enjoy nonsense humour significantly more than incongruity-resolution humour. Enjoyment of NON [unresolved] humour has also been found to be positively correlated with the openness to experience dimension (Martin 2006: 203).

For present purposes, it is enough to remark the equation of unresolved incongruity with enjoyment of unpredictability, on the one hand, and the identification of incongruity-resolution as an apparatus allowing attenuation of the disruption of semantic and temporal continuity on the other. Affect theory helps to make sense of these results, while the research around incongruity and resolution could provide greater precision and nuance to the study of laughter 
by affect scholars.

A further concrete example of such comic operations is provided by the concluding lines of the book The Philosophy of Andy Warhol by the artist and leading figure of the New York counterculture in the 1960s and early 1970 s.

"Because diamonds are forever," B said.

"Forever what?" (Warhol 1975: 241)

Exploiting the grammatical ambiguity attached to usage of the nominal adverb forever, Warhol's text ends with an unresolved joke, which has a profound effect upon the resonance of the book. It is radical in that sense, potentially transformatively so since the pleasurable temporal disjunction of laughter is all that is left. This creates, along with the interrogative, an open, pregnant futurity. If one attempts through interpretation to reduce Warhol's text as a whole to a coherent semantic content, one is likely to be frustrated by the constant disruptions of continuity throughout much of the book and to miss or understate the transformative affect that may be engendered by such unresolved comic interruptions.

Does this make the work, or any similar work, necessarily radical? Not essentially or inevitably so, since that depends upon the context and disposition informing reception. It could be conceived as a radical disruption and point of departure, but it could also be exploited as little more than a counterbalance to everyday logic and the stresses of continuity: comic relief. What can be said from Massumi's $(1995,2015)$ affect philosophical perspective, however, is that in generating laughter in a largely unredeemed dislocation of time through the subversion of productive meaning, it embodies transformative potential.

\section{Nomad thought: incongruity as radical difference}

The writing of Deleuze, a philosopher who substantially influenced affect theory, is useful for examining, and even extending, the notion of affective transformative potential in the comic. Without attempting to distil Deleuze's vast and evolving oeuvre, or to suggest it contains a unified comic theory, this section investigates the philosopher's depiction of transformative laughter emanating from unresolved dissonance. It suggests that by treating laughter and incongruity together, comic laughter might be conceived in ways that have not been thoroughly articulated by either affect philosophy or incongruity-based humour theory.

The following textual analysis is centred on Deleuze's essay "Nomad thought" (1977), which discusses the writing style of the philosopher Nietzsche, with some reference to the modernist writers Kafka and Beckett. All three are viewed as displaying radically comical elements that fundamentally subvert conventional social codes. Writing in the wake of the 1960s, Deleuze identifies them as "countercultural" and ascribes to them a free-ranging "nomadic" affect that is at once comical, transgressive and productive (Deleuze 1977: 147). Deleuze argues that engaging actively with these texts requires not just a sense of humour but a positive disposition towards the affect of laughter produced from the play of comic surfaces ("exteriority") (Deleuze 1977: 146). It follows Nietzsche's condemnation in Thus Spoke Zarathustra (1976) of a scholarly "spirit of gravity," and Zarathustra's exhortations to laughter as a means of transformation beyond one's self: in short, "learn to laugh away over yourselves!" (Nietzsche 1976: 406, 407). In "Nomad thought," Deleuze (1997: 147) states that "[t]hose who read Nietzsche without laughing - without laughing often, richly, even hilariously - have, in a sense, not read Nietzsche at all" and similarly emphasises the importance of laughter in response to Kafka and Beckett (Deleuze 1977: 147). 
Significantly for the present discussion of the affect of laughter in relation to the comic, the same passage of "Nomad thought" includes the brief sentence, "Laughter - and not meaning" (Deleuze 1977: 147), which is not explicated but is pivotal to the philosophical thesis. It might be reinscribed as "Affect - and not meaning." A remarkably similar statement was made around the same time by another pre-eminent Continental philosopher, Derrida; likewise drawing upon Nietzsche and acknowledging a debt to Deleuze's work (1998), Derrida (1978: 256) observes that a certain spontaneous comic laughter "bursts out only on the basis of an absolute renunciation of meaning." But in neither Derrida's case nor Deleuze's does this imply laughter divorced from the comic; nor does it imply pure comic nonsense. In "Nomad thought," Deleuze (1977: 147) remarks that "[f]or Nietzsche, laughter always refers to an exterior movement of irony and humour." Making sense of these statements will clarify conditions associated with the transformative laughter posited by such philosophies, and by implication laughter that may be considered less radical.

Firstly, some textual context is required. "Nomad thought" (Deleuze 1977) is concerned with how Nietzsche attempted to create a liberating philosophy that does not itself become another stultifying systematic delimitation of human endeavour. Deleuze (1977: 146) claims that Nietzsche achieves this in part through playful stylistic subversion of continuity, emotional "depth" and resolution. Nietzsche often writes aphoristically, in staccato bursts of prose that avoid the cumulative construction of an intellectual edifice. Deleuze characterises it as "continuous flux and the disruption of flux," and in this sense, the style is akin to that of jokes (and also Warhol's 1975 book).

According to Deleuze's (1977) essay, Nietzsche's prose seeks to evoke not merely intellectual but affective philosophical change by offering contradictory and competing interpretative paths. This is identified by Deleuze (1977: 147) as the source of laughter: "One cannot help but laugh when the codes are confounded,"1 a statement consistent with incongruitybased theories of the comic. What distinguishes Nietzsche's comic aphoristic style from everyday humour and comic relief that might support a status quo, according to Deleuze, is that affects are generated with minimal resolution. It is not nonsense, but proliferation of meanings or implications that are not decisively resolved at the moment of laughter, or resolved through laughter. Deleuze claims this creates uncertainty and thus "intensity," much as Massumi (2015: 8) observes in his discussion of interruptive affect.

A similar positive regard for comic "undecidibility" is attributed to Derrida by Segal (2018) and related to aporia. Although the two philosophers should not be conflated, both Deleuze and Derrida are negotiating a course between meaning and non-meaning, proclaiming the value of adventurously riding differences rather than seeking and depending upon conclusive determinations. This philosophy of ongoing transformation is identified by Derrida (1978) with deconstructive play (marked through the neologism différance) and by Deleuze (1977) with nomad thought and writing. As noted by Conway (2010: 132), the philosophical laughter affirming this existential mode is ranged principally against "the notion of closure as well as end."

Importantly, neither Deleuze nor Derrida rejects meaning as such or the value of textual analysis. "Nomad thought" observes of Nietzsche's style: "An aphorism is a matter of laughter and joy. If we have not discovered what it is in the aphorism that makes us laugh, what the distribution of humour and irony is, what the division of intensities is, then we have not found anything" (Deleuze 1977: 147-148). Discovering what "makes us laugh" implies interpretative

1 "On ne peut pas ne pas rire quand on brouille les codes" in the original (Deleuze 1973). Deleuze also converges with incongruity theory in his analysis of burlesque and Chaplin's comedy in Cinema I. There Deleuze (1986a: 169-172) repeatedly describes "distance" between juxtaposed conceptual frames-five times referring to "infinite distance," twice to "great distance," as well as "maximum distance" and "enormity of the distance." 
process, but the aim is not to fix an interpretation, which Deleuze associates negatively with "recodification"; the goal is rather to engender an affective shift. "Nomad thought" thus argues that "Nietzsche tells us not to barter away intensity for mere representations" (Deleuze 1977: 146), which is to say "Laughter - and not meaning" (Deleuze 1977: 147). The affective intensity is most important because it is not mere abstraction but embodied transformation, associated with nomadic, productive "deterritorialisation."

Since Deleuze's (1977) essay provides no specific textual examples from Nietzsche's work, it will be helpful to examine directly a short aphorism by Nietzsche to elucidate the comic writing strategy "Nomad thought" refers to. In Beyond Good and Evil, Nietzsche (1972: 82) writes this isolated sentence: "One is punished most for one's virtues." Interpreting this depends almost entirely upon how one reads the terms "punish" and "virtue." If one assumes conventional meanings of those terms, something is amiss: it is patently at odds with much conventional dogma (codification) and even common sense (also a set of codes). This sudden semiotic "crisis," causing temporal disjunction and perhaps laughter, also forces the application of greater intellectual resources, itself a form of intensification, to interpretation.

In that case, various possible interpretations might be generated: firstly, Nietzsche may be suggesting that by behaving virtuously according to conventional moral or ethical codes one receives "punishment" in the sense of being restricted in one's behaviour and in being disadvantaged socially in relation to those who are less virtuous; on the other hand, Nietzsche may be suggesting there are behaviours we may be punished for that in their own way are "virtuous," even if they are identified socially as the opposite through conventional moral, ethical, legal codes. In the first case, the term "punishment" is subjected to playful uncertainty; in the second case, it is the word "virtuous." Or, one could adopt a third route, acknowledging that both (and perhaps other) interpretations are possible. In any case, the differences are not simply binary, as typical of incongruity theories, but proliferating. Deleuze (1986b: 194) writes that "laughter, roars of laughter, affirm multiplicity and the unity of multiplicity." In effect, Deleuze here conceives comic "incongruity," where the prefix "in-" suggests negation, in the more positive terms of radical difference. ${ }^{2}$ Having given up confident dependence upon authoritatively encoded values (religious, ethical, rational) it renders uncertainty primordial, throwing moral categories and all categorical statements into an ongoing interaction of forces.

Most crucially, such a text (and those of Kafka and Beckett) leads the ideal Deleuzian reader to confront the act of codification at the most immediate and fundamental level. Although the confounding of codes is not decisively resolved - because the codes are not resolved - a positive, transformative existential intensification may be induced if one is so inclined. The notion of affirmative, embodied comic laughter derived from radical difference is seen to prevent uncertainty from succumbing to paralysing abstract relativism: choices may still be made, actions taken, but without prior authorisation. In philosophical terms, "Nomad thought" attempts a shift in emphasis from ontology toward ontogenesis, which is to say, from reactive being toward active becoming, the latter term now being foundational to affect philosophy (Gregg \& Seigworth 2010: 3). In "Nietzsche's burst of laughter," Deleuze (2004: 129, 130) refers to "a new dimension which operates both in time and against time" and is associated with "a kind of dissolution of the self," not once and for all but constantly, and with constant rebirth. It is described in Difference and Repetition as "the power of beginning and beginning again" (Deleuze 1995: 136). Because ontogenesis requires affective interruption (the "continuous flux [...] and interruption of flux"; see Deleuze 1977: 146), a certain comic laughter assumes a

2 This would include comic interruption through unexpected degrees of repetition. In Difference and Repetition Deleuze (1995: 91) observes that for Marx (1907) "repetition is comic when it falls short - that is, when instead of leading to metamorphosis and production of something new, it forms a kind of involution." This might be interpreted as meaning repetition becomes comic when it subverts an expected degree of change. 
special function. Since it can notionally be evoked anywhere, anytime, it serves as a positive embodiment of a nomadic existential orientation towards difference, newness, and endless transformation.

What Deleuze presents is speculative philosophy, not empirical fact, but it is not disconnected from reality. What is described can be related to certain personality traits associated with the unresolved and resolved comic by Hehl and Ruch (1990), for instance, and it should be testable as such. It is possible that contemporary individuals and cultures move to various degrees between these modes of being and becoming, and comic laughter's affect may function as a portal and positive reinforcement in either direction. This too warrants further investigation. By doing so, it should be possible to expand the range of study in the field to better understand and accommodate potentials of comic laughter that take us beyond familiar conceptions of what it means to laugh and, indeed, what it means to be human, to render comic laughter in the language of difference and becoming.

\section{Conclusion}

The preceding analysis has aimed to demonstrate the usefulness of examining affect in comic laughter through reference to incongruity, interruption, and the way in which difference is experienced. I see two main implications from this analysis for humour theory and affect philosophy. Firstly, while humour remains intimately related to its context and content, the concepts of incongruity and affective interruption are more than incidental, suggesting the value of continuing to pursue approaches to comic laughter that integrate the "comic" and "laughter," "the semiotic" and "affect." Secondly, it provides some tentative insight into differences between conservative, liberal and radical deployments of comically induced laughter. It suggests the benefit of pursuing better understanding of how comic laughter operates in service of vastly different modes of interacting with the world. It may also deepen understanding of complex movements and negotiations across those modes.

\section{Acknowledgements}

This research was undertaken with the support of a research "grant-in-aid" from the Japan Society for the Promotion of Science.

\section{References}

Amir, L. (2010). 'Humor and time', in Grant, S. (ed.), Time, Transcendence, Performance: Refereed Conference Proceedings, Melbourne: Monash University, pp. 1-31.

Attardo, S. \& Pickering, L. (2011). 'Timing in the performance of jokes'. Humor: International Journal of Humor Research 24 (2), pp. 233-250.

Bergson, H. (1911). Laughter: An Essay on the Meaning of the Comic. Brereton, C. \& Rothwell, F. (trans.). New York: Macmillan.

Braidotti, R. (2011). Nomadic Theory: The Portable Rosi Braidotti. New York: Columbia University Press.

Billig, M. (2005). Laughter and Ridicule: Towards a Social Critique of Humour. London: Sage. Brigstocke, J. (2014). The Life of the City: Space, Humour, and the Experience of Truth in Finde-siècle Montmartre. Farnham, Surrey: Ashgate Publishing. 
Conway, J. (2010). Gilles Deleuze: Affirmation in Philosophy. Palgrave Macmillan.

Critchley, S. (2002). On Humour. London: Routledge.

Deleuze, G. (1973). 'Pensé nomade', in Nietzsche-Aujourd'hui? 1. Intensités. Paris: Union Générale d'Editions.

Deleuze, G. (1977). 'Nomad thought', Allison, D. (trans.), in The New Nietzsche: Contemporary Styles of Interpretation, Allison, D. (ed.), New York: Dell Publishing, pp. 142-149.

Deleuze, G. (1983). Cinema 1: L'Image-Mouvement. Paris: Les Editions de Minuit.

Deleuze, G. (1986a). Cinema 1: The Movement-Image, Tomlinson, H. \& Habberjam, B. (trans.). Minneapolis: University of Minnesota Press.

Deleuze, G. (1986b). Nietzsche and Philosophy, Tomlinson, H. (trans.). London: Continuum.

Deleuze, G. (1995). Difference and Repetition, Patton, P. (trans.). New York: Columbia University Press.

Deleuze, G. (2004). 'Nietzsche's burst of laughter', in Desert Islands and Other Texts 19531974. Los Angeles: Semiotext(e).

Derrida, J. (1978). Writing and Difference, Bass, A. (ed. \& trans.). Chicago: University of Chicago Press.

Derrida, J. (1998). 'I'll have to wander all alone', Kammerman, D. (trans.), Tympanum. Retrieved 22 July 2018 from https://cengizerdem.wordpress.com/2009/12/01/ill-have-towander-all-alone-jacques-derrida/.

Eastman, M. (1937). Enjoyment of Laughter. London: Hamish Hamilton.

Emmerson, P. (2017). 'Thinking laughter beyond humour: Atmospheric refrains and ethical indeterminacies in spaces of care'. Environment and Planning A 49(9), pp. 2082-2098.

Emmerson, P. (2019). 'From coping to carrying on: A pragmatic laughter between life and death'. Transactions of the Institute of British Geographers 44, pp. 141-154.

Freud, S. (1960). Jokes and Their Relation to the Unconscious, Strachey J. (trans.). London: Routledge \& Kegan Paul.

Gregg, M. \& Seigworth G. (eds). (2010). The Affect Theory Reader. Durham, NC: Duke University Press.

Hall, K., Goldstein, D. \& Ingram, B. (2016). 'The hands of Donald Trump: Entertainment, gesture, spectacle'. HAU Journal of Ethnographic Theory 6 (2), pp. 71-100.

Hehl, F. \& Ruch, W. (1990). 'Conservatism as a predictor of responses to humour: III. The prediction of appreciation of incongruity resolution based humour by content saturated attitude scales in five samples'. Personality \& Individual Differences 11 (5), pp. 439-445.

Holt, E. \& Glenn, P. J. (2013). Studies of Laughter in Interaction. London: Bloomsbury Academy.

Hughes, S. M. (2016). 'Beyond intentionality: Exploring creativity and resistance within a UK Immigration Removal Centre'. Citizenship Studies 20, pp. 427-433.

Hynes, M. \& Scott S. (2010). 'Yea-saying laughter'. Parallax 16 (3), pp. 44-54.

Kant, I. (1952). The Critique of Judgement, Meredith, J. C. (trans.). Oxford: Clarendon Press.

Kimmel, L. (1998). 'Philosophy, literature, and laughter: Notes on an ontology of the moment'. Analecta Husserliana 56, pp. 175-184.

Koestler, A. (1964). The Act of Creation. New York: Penguin.

Lingis, A. (2005). Body Transformations: Evolutions and Atavisms in Culture. New York: Brunner-Routledge.

Martin, R. (2006). The Psychology of Humor: An Integrative Approach. New York: Elsevier. Marx, K. (1907). The Eighteenth Brumaire of Louis Bonaparte. Chicago: Charles H. Kerr.

Massumi, B. (1987). Foreword to A Thousand Plateaus: Capitalism and Schizophrenia. Massumi, B. (trans.). Minneapolis: University of Minnesota Press.

Massumi, B. (1995). 'The autonomy of affect'. Cultural Critique 31 (Fall), pp. 83-109. 
Massumi, B. (2015). The Politics of Affect. Cambridge, UK: Polity Press.

Morreall, J. (1983). Taking Laughter Seriously. New York: SUNY.

Morreall, J. (1989). 'Enjoying incongruity'. Humor: International Journal of Humor Research 2 (1), pp. 1-18.

Nancy, J. (2008). Discourse on the Syncope: Logodaedalus, Anton, S. (trans.). Stanford: Stanford University Press.

Nietzsche, F. (1976). Thus Spoke Zarathustra, in The Portable Nietzsche, Kaufmann W. (ed. \& trans.). Harmondsworth: Penguin Books.

Nietzsche, F. (1972). Beyond Good and Evil, Hollingdale, R. J. (trans.). Harmondsworth: Penguin.

Parvulescu, A. (2010). Laughter: Notes on a Passion. Cambridge, MA: MIT Press.

Plessner, H. (1970). Laughing and Crying: A Study in the Limits of Human Behavior. Evanston, IL: Northwestern University Press.

Postman, N. (1985). Amusing Ourselves to Death: Public Discourse in the Age of Show Business. Harmondsworth: Penguin.

Provine, R. (2000). Laughter: A Scientific Investigation. New York: Penguin.

Raskin, V. (1985). The Semantic Mechanisms of Humor. Boston: Reidel.

Ritchie, G. (1999). 'Developing the incongruity-resolution theory', Informatics Research Report EDI-INF-RR-0007. Edinburgh: University of Edinburgh. Retrieved 12 July 2018 from https://www.era.lib.ed.ac.uk/handle/1842/3397.

Routledge, P. (2012). 'Sensuous solidarities: Emotion, politics and performance in the clandestine insurgent rebel clown army'. Antipode 44, pp. 428-452.

Ruch, W. \& Hehl, F. (1986a). 'Conservatism as a predictor of responses to humour: I. A comparison of four scales'. Personality \& Individual Differences 7 (1), pp. 1-14.

Ruch, W. \& Hehl, F. (1986b). 'Conservatism as a predictor of responses to humour: II. The location of sense of humour in a comprehensive attitude space'. Personality \& Individual Differences 7 (6), pp. 861-874.

Segal, A. (2018). 'Jokes, aporia and undecidability'. The European Journal of Humour Research $6(1)$, pp. $1-11$.

Spinoza, B. (1994). Ethics, Curley, E. (trans.). London: Penguin Books.

Sulejmanov, F., Spasovski, O. \& Platt, T. (2018). 'The development of the Humour Structure Appreciation Scale and its relation to Sensation Seeking Inventory and Need for Closure Scale'. The European Journal of Humour Research 6 (1), pp. 124-140.

Taibbi, M. (2017). Insane Clown President: Dispatches from the American Circus. London: Penguin.

Warhol, A. (1975). The Philosophy of Andy Warhol: From A to B and Back Again. New York: Harcourt.

Weeks, M. (2002). 'Laughter, desire and time'. Humor: International Journal of Humor Research 15 (4), pp. 383-400.

Weeks, M. (2013). 'Abandoning our selves to laughter: Time and the question of self-loss in laughter'. Israeli Journal of Humor Research 3, pp. 58-75. 